\title{
NEWS OF NATIONAL SOCIETIES
}

Formerly: International Bulletin of Red Cross Societies, founded in 1869

\section{Spain}

We should like to thank the Spanish Red Cross for sending us the following article, which gives interesting details concerning the organization of the hospital establishments in its charge. In this connection, we also wish to remind our readers that the July 1956 issue of the Revue internationale contained an article on the Central Hospital of the Spanish Red Cross.

The Central Hospital establishments in Madrid, consisting of the "San Jose y Santa Adela" Hospital, the Central Dispensary and the Central Nurses' School, are run by the Spanish Red Cross.

The Hospital contains the most modern installations and comprises 350 beds, divided among the general, medical and surgical wards for men and women, where the following special branches are treated : general surgery, urology, cardiology, neurology, otorhinolaryngology, general medicine, endocrinology, heart and lung surgery ; in addition, there are special gynaecological and maternity wards, children's and ophthalmologic wards.

The surgical department contains five operating theatres, rooms for making plaster casts, others for preparing, sterilizing and storing instruments, anaesthetics rooms and a rest-room. Private rooms are placed at the disposal of head doctors, assistant doctors and nurses, and there is also a conference hall.

The Dispensary was inaugurated in 1928 by Queen Victoria Eugenia, who was at that time Supreme Head of the Spanish Red Cross. It contains the following special departments : otorhinolaryngology, urology, gynaecology, obstetrics, general surgery, neurology, oncology, X-rays (four modern units), dermatology, syphilis, dental department, general medicine with complete installations for the examination of metabolism and special bio-physical 
research laboratories, hematologic and blood transfusion laboratory, chemical laboratory, departments for diseases of the digestive system, heart and lungs, convalescence, children's section (with an artificial beach) and social welfare.

The Central Nurses' School provides training for professional nurses and for the institution's voluntary aids. The first school for professional Red Cross nurses was created in Madrid by the Central Committee in 1918 with a house of residence for the nurses. The first students completed their training in 1923. Subsequently, the Committee set up a similar school in Barcelona in 1920, and another in Seville in 1947. Earlier, in 1917, it had created a corps of (female) voluntary aids, who passed the first examinations in Madrid in May of the same year. All the provincial committees and most of the regional committees have organized similar training.

The professional nurses' schools are organized as residential schools. The training, directed by the "Daughters of Charity", lasts three years. Qualified Red Cross nurses also act as teachers and instructors. To be admitted to one of these schools, students must be between 17 and 30 years of age, single or widows without children, and possess at least the lower school-leaving certificate. Applicants who do not have the higher school-leaving certificate (bachillerato superior), the national teachers diploma or a commercial school certificate, must undergo an entrance examination. The others must pass a qualifying medical test in order to be accepted. The first term or preliminary course is eliminatory and ends with final entrance examinations which all the students are obliged to take.

During the three years' training, the students work from one to three months (depending on the importance of the branch) in each department. Moreover, they spend 90 days on night-duty during their training. Practical courses alternate with theoretical training, according to the programme drawn up on the model of the official programme for technical hospital assistants, studied in the Faculty of Medicine and published in 1958 by the National Education Ministry.

During their training, the student nurses sit for end-of-term examinations, as well as a general examination at the end of the school year, in June. A special jury is appointed by the school 
Board, in agreement with the Central Committee, for the final examinations conferring the diploma of Professional Red Cross Nurse, whereas the Faculty of Medicine appoints the jury for the Technical Hospital Assistant examinations. If a student fails in one of the end-of-term examinations, she cannot sit for the annual examination in June.

The training courses for voluntary aids last two years, during which time the candidates have to carry out 120 days of practical work per year and attend the theoretical courses according to a special programme drawn up by the Society. These take place in the mornings only, either at the Hospital or the Dispensary. The examinations are held in June in the presence of a jury appointed by the School Board in agreement with the Central Committee of the Spanish Red Cross.

\section{United States}

The American Red Cross has produced a folder entitled " Henry Dunant, Red Cross Prophet ". This is a publication which shows the founder of the Red Cross as he really was and as he appears from a reading of documentary sources. In the last part, Dunant's influence is placed in a just light, as is the profound significance of his message; the final section ends with these words: "The moral energy of Dunant made him the prophet of the Red Cross. His craving to bring relief to humanity in pain has made itself felt throughout the world."

With the approach of the Red Cross Centenary, it is necessary to go back to the origins and that is why we think it will be of interest to reproduce the contents of this folder on Dunant's life and work.

The force that drew many men and nations together in the Red Cross movement was supplied by Henri Dunant of Geneva, 